\title{
Persistence and Effect of Processing on Reduction of Chlorpyriphos in Chilli
}

\author{
Kumari B*and Chauhan R
}

Department of Entomology, Chaudhary Charan Singh Haryana Agricultural University, Hisar-125004, Haryana, India

\begin{abstract}
Persistence behavior of chlorpyriphos in chilli was studied following application of formulation of 20 EC @ 160 (single dose) and 320 (double dose) g a.i.ha ${ }^{-1}$ at fruiting stage. Samples of green chilli and soil under crop were drawn at different time intervals and quantified by gas liquid chromatography equipped with electron capture detector. The initial deposits of residue on the chilli fruit were 0.397 and $1.021 \mathrm{mg} \mathrm{kg}^{-1}$ at single and double dose, respectively. Residues of chlorpyriphos dissipated to more than $75 \%$ after 10 days at both the dosages. The half-life period of chlorpyriphos in chilli was recorded to be 6.02 days at single dose and 5.67 days at double dose. Washing process was found effective in reducing the residues by 67.75 and 71.60 percent at, respective doses.
\end{abstract}

Keywords: Chlorpyriphos; Chilli; Residues; Persistence; Half-life; Washing; Soil

\section{Introduction}

Pesticides help the farmers to increase their income by improving the quality of crop, saving crop losses, increase crop productivity and reduce cost of production. In recent years, the role and contribution of pesticides have increased much more, especially in the country like India because of fast growth of population; the demand for food supply will continue to grow steadily. Due to regular use of pesticides, the residues in food commodities seldom exceed the maximum residue limits (MRLs) set by the food authorities. As a result, consumption of pesticide treated food commodities become risky. So it becomes necessary that, pesticide should be effective against pest along with its toxicologically acceptable residues in food commodity [1]. For this reason, proper assessing of pesticide residues is very important for reducing health hazard to consumers. Chilli (Capsicum annum) is an essential pillar of the cuisines of India. It is attacked by various insect pests resulting in yield losses. The crop is attacked by various insect pests resulting 51 species of insects and 2 species of mites. Thrips, mites and pod borer are serious among its pests [2].

Chlorpyriphos [O,O-diethyl-O-(3,5,6-trichloro-2-pyridinyl) phosphorothionate] is an organo phosphorus broad spectrum insecticidal active ingredient registered for application to more than 40 different food commodities. It is a stable compound in neutral and acidic conditions [3]. It kills insects by disrupting their nervous system and is effective against both sucking and chewing insects and has been widely used to control pests of various vegetables [4]. It is non-systemic, fairly persistent, and highly soluble in organic solvents like acetone, xylene, and methylene chloride [5]. Cholinesterase inhibition is the mode of action of chlorpyriphos and is the cause of potential toxicity in human $[6,7]$.

There is currently an increasing concern and awareness about the hazards of pesticides to consumers. Even with the adoption of integrated pest management, farmers believe in the control of pests using pesticides because of their quick effect. Therefore, the present study was designed to determine the residual persistence and effect of processing on reduction of chlorpyriphos residues in chilli.

\section{Materials and Methods}

\section{Chemicals and reagents}

Chlorpyriphos formulation (20 EC) used for field application was procured from local market. Solvents and reagents like dichloromethane, acetone, sodium chloride, and anhydrous sodium sulfate all were procured from Merck (Darmstadt, Germany). Before use all the common solvents were redistilled in glass apparatus. By running reagent blanks the suitability of all the solvents was ensured before actual analysis.

\section{Field experiment}

The crop was raised at the Research Farm of Chaudhary Charan Singh Haryana Agricultural University (CCSHAU), Hisar following recommended agronomic practices. Plot size was $25 \mathrm{~m}^{2}$ with spacing $60 \times 30 \mathrm{~cm}$ (rows $\times$ plants) in triplicate with randomized block design (RBD). Before spraying, chilli fruits (Variety: HPH-2024) in all plots/ replicates were tagged and sprayed with chlorpyriphos $20 \mathrm{EC}$ using knap sap sprayer at single dose $\left(160 \mathrm{~g}_{\text {a.i }} \mathrm{ha}^{-1}\right)$ and double dose (320 g a.i ha ${ }^{-1}$ ) along with a control plot where no insecticide was applied. The volume of water used at the time of spray was @ 500 Lha $^{-1}$.

The soil under crop was of light texture with low content of organic matter; other relevant properties of the soil were EC $2 \mathrm{dSm}^{-1} ; \mathrm{K} 10.08$, $\mathrm{P}_{2} \mathrm{O}_{5} 15 \mathrm{~kg} \mathrm{ha}^{-1}$ with $\mathrm{pH} 7.6$ and organic carbon 0.67 percent.

\section{Sampling}

The composite sample about $250 \mathrm{~g}$ of tagged chilli fruits were collected randomly separated from the control and treated plots of each treatment at 0 ( $1 \mathrm{hr}$ after spray), 1, 3, 5, 7, 10, 15 and 30 days after the application of insecticide, packed in paper bags, and brought to the laboratory for processing. In the laboratory the samples were divided in two lots, one was processed as such and other was kept to study the effect of washing on reduction of residues. After thorough mixing and quartering of each part, $25 \mathrm{~g}$ representative sample of chilli was used for processing and analysis.

*Corresonding author: Kumari B, Department of Entomology, Chaudhary Charan Singh Haryana Agricultural University, Hisar-125004, Haryana, India, E-mail: beenakumari.958@rediffmail.com

Received June 30, 2015; Accepted July 21, 2015; Published July 28, 2015

Citation: Kumari B, Chauhan R (2015) Persistence and Effect of Processing on Reduction of Chlorpyriphos in Chilli. J Food Process Technol 6: 497. doi:10.4172/2157-7110.1000497

Copyright: (C) 2015 Kumari B, et al. This is an open-access article distributed unde the terms of the Creative Commons Attribution License, which permits unrestricted use, distribution, and reproduction in any medium, provided the original author and source are credited. 
Soil samples $(500 \mathrm{~g})$ under crop were also collected separately from 5-10 different sites with the help of a steel auger from the depth of $0-15 \mathrm{~cm}$. Soil collected from different sites was pooled and sieved to remove extraneous matter, including stones/pebbles. After thorough mixing, a sub sample of about $250 \mathrm{~g}$ was taken from pooled sample of each treatment and transported to the laboratory. The samples were processed and analyzed at the Pesticide Residue Laboratory, Department of Entomology, CCS HAU, Hisar.

\section{Extraction}

Residues of chlorpyriphos from chilli were extracted by adopting the method of Bhardwaj et al. [7]. Representative $25 \mathrm{~g}$ sample of chilli was chopped into small pieces and macerated in mixer grinder and shaken with acetone $(100 \mathrm{ml})$ on mechanical shaker for $1 \mathrm{hr}$ and kept overnight in an Erlenmeyer flask. Extract was filtered through 2-3 $\mathrm{cm}$ layer of anhydrous sodium sulphate and the filter was washed with acetone $(2 \times 10 \mathrm{ml})$. The filtrate was subjected to liquid-liquid partitioning in 1-L separator funnel and diluted with 4-5 times brine solution ( $10 \%$ sodium chloride solution), and the contents partitioned first with dichloromethane $(75,75 \mathrm{ml})$ and then with hexane $(75,75$ $\mathrm{ml}$ ). Combined both the fractions and treated with $300 \mathrm{mg}$ activated charcoal powder for about 2-3 hrs at room temperature. When the solution became clear, it was filtered through Whatman filter paper no.1. The clear extract was concentrated using a rotary vacuum evaporator. The extract was finally made up to $2 \mathrm{ml}$ and added to the liquid - solid chromatography column.

\section{Clean-up}

Clean-up of samples was done by using column chromatography. Glass columns $(60 \mathrm{~cm} \times 22 \mathrm{~mm}$ i.d) were packed compactly with silica gel sand-witched in between two layers of anhydrous sodium sulphate. Prepared column were pre-washed using $40 \mathrm{ml}$ hexane. The column was loaded with the concentrated extract and eluted with a solution of hexane: acetone $(9: 1 \mathrm{v} / \mathrm{v})$. Combined the organic phases and concentrated to about $5 \mathrm{ml}$ on a rotary vacuum evaporator. Finally, the extract was concentrated to dryness on gas manifold evaporator and final volume was made to $2 \mathrm{ml}$ in $\mathrm{n}$-hexane and analyzed by GC.

\section{Washing}

The whole fruits of chilli were washed under running tap water for $1 \mathrm{~min}$ by gentle rubbing with hands and the water was discarded. These washed samples were kept on blotting paper just to remove the excess of water following method of Walter et al. [8]. Then the samples were extracted, cleaned up in a similar manner as the raw samples were processed and analyzed.

\section{Soil}

Ground, sieved and dry representative (15 g) sample was mixed with 1-2 drops of ammonia solution and left for half an hour. Mixed the soil thoroughly with $0.3 \mathrm{~g}$ activated charcoal, $0.3 \mathrm{~g}$ Florisil and $10 \mathrm{~g}$ of anhydrous sodium sulphate and packed compactly in a glass column $(60 \mathrm{~cm} \times 22 \mathrm{~mm}$ i.d) in between two layers of anhydrous sodium sulphate as per method of Kumari et al. [9]. Residues were eluted with $125 \mathrm{ml}$ solution of hexane: acetone $(9: 1 \mathrm{v} / \mathrm{v})$ at flow rate of $\mathrm{mL} \mathrm{min}^{-1}$. The elute was concentrated on rotary vacuum evaporator and made the final volume to $2 \mathrm{ml}$ in $\mathrm{n}$-hexane for GC analysis.

\section{Estimation by gas liquid chromatography}

The cleaned extracts analyzed on gas chromatograph (Shimadzu-2010) equipped with ${ }^{63} \mathrm{Ni}$ electron capture detector
(ECD) and HP-1 capillary column provide good results. Operating conditions were as per details: Temperature $\left({ }^{\circ} \mathrm{C}\right)$ : Oven: $150\left(5 \mathrm{~min}^{-1}\right)$ $\rightarrow 8 \mathrm{~min}^{-1} \rightarrow 190(2 \mathrm{~min}) \rightarrow 15 \mathrm{~min}^{-1} \rightarrow 280(10 \mathrm{~min})$, Injection port: $280^{\circ} \mathrm{C}$ and detector: $300^{\circ} \mathrm{C}$. Flow rate of nitrogen (carrier gas) was maintained at $60 \mathrm{ml} \mathrm{min}{ }^{-1}$ and through column $2 \mathrm{ml} \mathrm{min}^{-1}$ with split ratio 1:10. Under these operating conditions, the retention time of chlorpyriphos was found to be $13.991 \mathrm{~min}$. The residues of chlorpyriphos in samples were identified and quantified by comparing retention time and area of sample chromatograms with that of standards run under identical conditions.

Chilli and soil samples were spiked with chlorpyriphos at two concentration levels $\left(0.010\right.$ and $\left.0.025 \mathrm{mg} \mathrm{kg}^{-1}\right)$ processed and analyzed as per the methodology described above to check the validity of the method. Percent recoveries in chilli were 90.50 and 92.10 while in soil were 92.70 and 93.95 at two fortification levels, respectively. As the percent recovery obtained were more than $90 \%$, therefore, the results have been presented as such without applying any correction factor. Limit of determination/quantification (LODe/LOQ) was $0.010 \mathrm{mg} \mathrm{kg}^{-1}$.

\section{Results and Discussion}

The results of chlorpyriphos residues after application @ 160 and $320 \mathrm{~g}$ a.i.ha ${ }^{-1}$ detected in chilli samples collected from the Research Farm of CCS HAU, Hisar are presented in Table 1. The results indicated that at raw stage the highest chlorpyriphos residues were found in chilli. The initial deposits of chlorpyriphos at single and double dose were observed to be 0.397 and $1.021 \mathrm{mg} \mathrm{kg}^{-1}$, respectively. In the start, residues dissipated slowly i.e. $0.385,0.278$ and 0.180 in case of single dose while $0.997,0.695$ and 0.485 in case of double dose on 1, 3 and $5^{\text {th }}$ day after application. The residues reached below detectable levels $\left(0.010 \mathrm{mg} \mathrm{kg}^{-1}\right)$ on $15^{\text {th }}$ and $30^{\text {th }}$ days of treatment in single dose and double dose, respectively, showing per cent dissipation of 97.48 and 98.14 per cent. Residue data were subjected to statistical analysis for computation of regression equations, half-life $\left(t_{1 / 2}\right)$ values and percent degradation. The residues dissipated with half-life period of 6.02 days at single dose and 5.67 days at double dose. Residues of chlorpyriphos did not follow the first order kinetics. But the residues followed the pseudo first order kinetics $\left(\mathrm{R}^{2}\right)$ with 0.900 and 0.856 for single and double dose, respectively. Subhash et al. [10] studied the persistence behavior of chlorpyriphos, cypermethrin and monocrotophos in okra. The residues of all the three insecticides reached below detection limit (BDL) showing complete dissipation with in 15, 17 and 19 days respectively, when it was applied 100,200 and $300 \mathrm{~g}$ a.i. $\mathrm{h}^{-1}$. Jyot et al. [2] reported that the average initial deposits of chlorpyriphos on chilli were 0.59 and $2.02 \mathrm{mg} \mathrm{kg}^{-1}$ following the application of chlorpyriphos at 500 and 1,000 ga.i.ha ${ }^{-1}$. These residues reached below the determination limit of $0.01 \mathrm{mgkg}^{-1}$ after the $10^{\text {th }}$ and $15^{\text {th }}$ with half-life period of 4.43 and 2.01 days at single and double doses, respectively. Samriti et al. [11] observed that when chlorpyriphos applied on okra @ 200 and $400 \mathrm{~g}$ a.i $\mathrm{ha}^{-1}$, residues on $7^{\text {th }}$ and $15^{\text {th }}$ day of application reached below detection limit (BDL) of $0.010 \mathrm{mg} \mathrm{kg}^{-1}$ in single and double dose, respectively and reported half-life period of 3.15 days at single dose and 3.46 days at double dose following first order kinetics. Similar type of observation with chlorpyriphos in chilli was reported by Waghulde et al. [12] Present results seem to be in conformation with earlier reports.

\section{Effect of processing}

Chilli fruits were subjected to processing like washing in order to investigate the reduction of residues up to $5^{\text {th }}$ day of sampling. The results pertaining to the effect of washing on the removal of chlorpyriphos residues applied at 160 and $320 \mathrm{~g}$ a.i. ha ${ }^{-1}$ on chilli fruits 
Citation: Kumari B, Chauhan R (2015) Persistence and Effect of Processing on Reduction of Chlorpyriphos in Chilli. J Food Process Technol 6: 497. doi:10.4172/2157-7110.1000497

Page 3 of 4

are presented in Table 2. It has been found that washing was found effective in reducing the residues on $0(1 \mathrm{~h})$ days after application. The average initial deposits of chlorpyriphos was 0.397 and $1.021 \mathrm{mg} \mathrm{kg}^{-1}$ at single and double dose on chilli fruits were reduced to 0.128 and $0.290 \mathrm{mg} \mathrm{kg}^{-1}$ as a result of simple washing with tap water showing the loss of 67.75 and 71.60 percent at, respective doses. In case of third day samples, the residues were reduced to 0.180 and $0.425 \mathrm{mg} \mathrm{kg}^{-1}$ thereby, accounted 35.25 and 38.84 percent residues loss at single and double doses, respectively. Sunayana et al. [13] studied the effect of washing alone with tap water to check the percent reduction in residues of chilli, when fipronil was applied on chilli crop @ 50 and $100 \mathrm{~g}$ a.i.ha ${ }^{-1}$. As a result of simple washing percent reduction was observed 42.05 and 45.42 at single and double dose respectively. Rani et al. [14] reported that processing was very effective in reducing the residues of chlorpyriphos in tomato fruits when applied @ 400 and $800 \mathrm{~g}$ a.i. ha ${ }^{-1}$. Samriti et al. [11] reported that due to washing $13-35 \%$ reduction of chlorpyriphos was observed in okra when applied @ 200 and 400 g a.i. ha ${ }^{-1}$.

\section{Chlorpyriphos residues in soil samples}

In soil, initial deposit of chlorpyriphos on 0 ( $1 \mathrm{~h} \mathrm{after} \mathrm{treatment)}$ days at single dose was $0.439 \mathrm{mg} \mathrm{kg}^{-1}$ and $0.903 \mathrm{mg} \mathrm{kg}^{-1}$ at double dose (Table 3). Under study period of 30 days, residues reached to the levels of 0.037 and $0.088 \mathrm{mg} \mathrm{kg}^{-1}$ at single and double dose, respectively. The dissipation after 30 days was observed to be 91.57 per cent for single dose and 90.25 per cent for double dose.
Jyot et al. [2] reported that residues of chlorpyriphos and cypermethrin were found to be $<0.01 \mathrm{mg} \mathrm{kg}^{-1}$ for both these insecticides

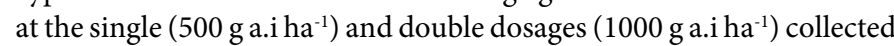
15 days after the last spray. Persistence of chlorpyriphos in soil under tomato crop was studied by Rani et al. [14] with active application of chlorpyriphos at 400 and $800 \mathrm{~g}$ a.i. ha $^{-1}$. In soil samples, residues of chlorpyriphos reached below detectable level of $0.010 \mathrm{mg} \mathrm{kg}^{-1}$ after 5 and 10 days after spray at single and double dose, respectively. Samriti and Kumari [3] reported that the residues of chlorpyriphos in soil under okra crop dissipated below determination level of $0.005 \mathrm{mg} \mathrm{kg}^{-1}$ on 5 days at single dose (200 g a.i ha $\left.{ }^{-1}\right)$ and 7 (400 g a.i ha-1 $)$ days at double dose reported.

\section{Conclusion}

From the above outcome, it is obvious that the application of pesticides in agriculture is necessary for better crop production against the possible health hazards arises due to the presence of pesticide residues in food. The half-life values for chlorpyriphos following three applications at the single and double dose on chilli fruits were observed to be 6.02 and 5.67 days, respectively. The residues of chlorpyriphos studied in chilli at two doses, reached to below detectable value of $0.01 \mathrm{mg} \mathrm{kg}^{-1}$ on $15^{\text {th }}$ and $30^{\text {th }}$ in single and double dose, respectively. Meticulous processing with simple household practices like washing, dislodged the residues by $68-72$ per cent and thereby ensures the safety of the chilli fruits to the consumers.

\begin{tabular}{|c|c|c|c|c|}
\hline \multirow{3}{*}{ Days after treatment } & \multicolumn{4}{|c|}{ Residue (mg kg-1) } \\
\hline & \multicolumn{2}{|c|}{ Single Dose (160 g a.i. ha-1) } & \multicolumn{2}{|c|}{ Double Dose (320 g a.i. ha-1) } \\
\hline & Average & $\%$ Dissipation & Average & \% Dissipation \\
\hline $0(1 \mathrm{~h})$ & $0.397 \pm 0.101$ & - & $1.021 \pm 0.226$ & - \\
\hline 1 & $0.385 \pm 0.017$ & 3.02 & $0.997 \pm 0.098$ & 2.35 \\
\hline 3 & $0.278 \pm 0.033$ & 29.97 & $0.695 \pm 0.111$ & 31.92 \\
\hline 5 & $0.180 \pm 0.016$ & 54.65 & $0.485 \pm 0.015$ & 52.49 \\
\hline 7 & $0.134 \pm 0.010$ & 66.24 & $0.360 \pm 0.085$ & 64.74 \\
\hline 10 & $0.085 \pm 0.012$ & 78.58 & $0.258 \pm 0.032$ & 74.73 \\
\hline 15 & $0.010 \pm 0.007$ & 97.48 & $0.019 \pm 0.007$ & 98.14 \\
\hline 30 & BDL & - & $\mathrm{BDL}$ & - \\
\hline \multicolumn{3}{|c|}{$t_{1 / 2}=6.02$ days } & \multicolumn{2}{|c|}{$\mathrm{t}_{1 / 2}=5.67$ days } \\
\hline
\end{tabular}

BDL: $0.01 \mathrm{mg} \mathrm{kg}^{-1}$

Table 1: Persistence and dissipation of chlorpyriphos residues in chilli.

\begin{tabular}{|c|c|c|c|c|c|c|}
\hline \multirow{3}{*}{ Days after treatment } & \multicolumn{6}{|c|}{ Residue (mg kg-1) } \\
\hline & \multicolumn{3}{|c|}{ Single Dose (160 g a.i. ha-1) } & \multicolumn{3}{|c|}{ Double Dose (320 g a.i. ha-1) } \\
\hline & Initial residues \pm SD & Washing \pm SD & $\%$ Reduction & Initial residues \pm SD & Washing \pm SD & $\%$ Reduction \\
\hline $0(1 \mathrm{~h})$ & $0.397 \pm 0.101$ & $0.128 \pm 0.110$ & 67.75 & $1.021 \pm 0.226$ & $0.290 \pm 0.031$ & 71.60 \\
\hline 1 & $0.385 \pm 0.017$ & $0.157 \pm 0.012$ & 59.22 & $0.997 \pm 0.098$ & $0.354 \pm 0.101$ & 64.49 \\
\hline 3 & $0.278 \pm 0.033$ & $0.180 \pm 0.016$ & 35.25 & $0.695 \pm 0.111$ & $0.425 \pm 0.111$ & 38.84 \\
\hline 5 & $0.180 \pm 0.016$ & BDL & - & $0.485 \pm 0.015$ & $0.405 \pm 0.075$ & 16.49 \\
\hline
\end{tabular}

Table 2: Effect of processing on chlorpyriphos residues $\left(\mathrm{mg} \mathrm{kg}^{-1}\right)^{*}$ in chilli.

\begin{tabular}{|c|c|c|c|c|}
\hline \multirow{3}{*}{ Days after treatment } & \multicolumn{4}{|c|}{ Residue (mg kg-1) } \\
\hline & \multicolumn{2}{|c|}{ Single Dose (160 g a.i. ha-1) } & \multicolumn{2}{|c|}{ Double Dose (320 g a.i. ha-1) } \\
\hline & Average & $\%$ Dissipation & Average & $\%$ Dissipation \\
\hline $0(1 \mathrm{~h})$ & $0.439 \pm 0.011$ & - & $0.903 \pm 0.012$ & - \\
\hline 3 & $0.304 \pm 0.013$ & 30.75 & $0.635 \pm 0.006$ & 29.67 \\
\hline 7 & $0.149 \pm 0.008$ & 66.05 & $0.315 \pm 0.023$ & 65.11 \\
\hline 15 & $0.078 \pm 0.006$ & 82.23 & $0.165 \pm 0.010$ & 81.72 \\
\hline 30 & $0.037 \pm 0.006$ & 91.57 & $0.088 \pm 0.007$ & 90.25 \\
\hline
\end{tabular}

Table 3: Persistence and dissipation of chlorpyriphos residues in soil. 
Citation: Kumari B, Chauhan R (2015) Persistence and Effect of Processing on Reduction of Chlorpyriphos in Chilli. J Food Process Technol 6: 497. doi:10.4172/2157-7110.1000497

\section{Acknowledgments}

The authors wish to express their gratitude to the Head, Department of Entomology for providing research facilities.

\section{References}

1. Singh G, Singh B, Battu RS, Jyot G, Singh B, et al. (2007) Persistence of ethion residues on cucumber, Cucumis sativus (Linn.) using gas chromatography with nitrogen phosphorus detector. Bull Environ Contam Toxicol 79: 437-439.

2. Jyot G, Kousik M, Battu RS, Singh B (2013) Estimation of chlorpyrifos and cypermethrin residues in chilli (Capsicum annuum L.) by gas-liquid chromatography. Environ Monit Assess 185: 5703-5714.

3. Chauhan SR, Beena K (2012) Persistence of chlorpyrifos in Okra (Abelmoschus esculentus) fruits and soil.Toxicol Environ Chem 94: 1726-1734.

4. Atif MR, Anjum MF, Ahmed A, Saqib RM (2007) Field incurred chlorpyrifos and 3,5,6-trichloro-2-pyridinol residues in fresh and processed vegetables. Food Chem 103: 1016-1023.

5. (2000) Office of prevention, pesticides and toxic substance chlorpyrifos Revised product and residue chemistry chapters. US Environmental Protection Agency, Washington DC

6. Oliver GR, Bolles HG, Shurdut BA (2000) Chlorpyriphos: Probabilistic assessment of exposure and risk. Neurotoxicology 21: 203-208.
7. Bhardwaj U, Kumar R, Kaur S, Sahoo SK, Mandal K, et al. (2012) Persistence of fipronil and its risk assessment on cabbage, Brassica oleracea var. capitata L. Ecotoxico Environ Safety 79: 310-308.

8. Walter JK, Arsenault TL, Pylypiw HM, Mattina MJI (2000) Reduction of pesticide residue on produce by rinsing. J Agric Food Chem 48: 4666-4670.

9. Kumari B, Madan VK, Kathpal TS (2008) Status of insecticide contamination of soil and water in Haryana, India. Environ Monit Assess 136: 239-244.

10. Subhash C, Mukesh K, Anil MN, Shinde LP (2014) Persistence pattern of chlorpyriphos, cypermethirn and monocrotophos in Okra. Internat J Advanc Res 2:738-743.

11. Reena SC, Beena K (2011) Persistence and effect of processing on reduction of chlorpyriphos residues in Okra fruits. Bull Environ Contam Toxicol 87:198-201.

12. Waghulde PN, Khatik MK, Patil VT, Patil PR (2011) Persistence and dissipation of pesticides in chilly and Okra at North Maharashtra Region. Pestic Res J 23: 23-26.

13. Sunayana S, Beena SK (2015) Persistence and effect of processing on fipronil 1 and its metabolites residues in Chilli (Capsicum Annum Linn). Pestic Res J 101409

14. Mamta R, Sunayana S, Beena K (2013) Persistence and effect of processing on chlorpyriphos residues in tomato (Lycopersicon esculantum Mill). Ecotoxico Environ Safety 95: 247-252. 